\title{
Treatment Outcomes in Chronic Myeloid Leukemia: Does One Size Fit All?
}

\author{
Alejandro Garcia-Horton, $M D,{ }^{1}$ and Jeffrey $\mathrm{H}$. Lipton, $\mathrm{MD}, \mathrm{PhD}^{1}$
}

\begin{abstract}
With the success of tyrosine kinase inhibitors (TKIs) in achieving next-to-normal overall survival in chronic myeloid leukemia (CML), treatment-free remission (TFR) has become a significant goal in the management of this disease. Discontinuation of therapy is attractive to both patients and physicians because maintaining a stable BCR$A B L$ transcript level without therapy would imply true operational $C M L$ cure. With TFR, patients are not exposed to unknown long-term adverse effects of TKIs and common adverse effects that may affect quality of life. Several factors need to be considered before attempting TFR, because this goal is not appropriate for a significant proportion of patients with CML. Patient-related factors, CML response to therapy and its duration, monitoring capacity, patient preferences and compliance with monitoring, and economic factors influence the decision to attempt to discontinue TKIs. Unfortunately, only $50 \%$ of patients are appropriate candidates for discontinuation of treatment. Of those, another $50 \%$ maintain stable disease while off TKls. This means that merely $25 \%$ of patients achieve TFR. Further optimization and research are required to be able to extend this treatment goal to a larger population of patients. Although TFR is attractive and desirable, this goal is not a one-size-fits-all approach, and we should continue to focus on patients with CML having a normal OS with the best quality of life possible.
\end{abstract}

J Natl Compr Canc Netw 2020;18(10):1421-1428 doi: $10.6004 /$ jnccn.2020.7627

${ }^{1}$ Division of Medical Oncology and Hematology, Princess Margaret Cancer Centre - University Health Network, University of Toronto, Toronto, Ontario, Canada.
The prognosis of chronic myeloid leukemia (CML) has greatly improved since the clinical use of tyrosine kinase inhibitors (TKIs) started with imatinib in the early 2000s. ${ }^{1}$ It is now considered a chronic disease, with its incidence being stable and prevalence increasing due to prolonged survival. ${ }^{2,3}$ Life expectancy has approached that of the general population, with 5-year survival only slightly lower in patients with CML. ${ }^{4}$ This benefit is observed in all age groups, but especially in patients as young as 55 years. ${ }^{5}$ The main reason for patients not reaching general population life expectancy seems to lie in the increased incidence of other malignancies and cardiovascular morbidity. ${ }^{5-9}$ This milestone, however, would never have been possible without widespread treatment and availability of TKIs, resulting in disease control and molecular response.

Treatment-free remission (TFR) has emerged as a new goal for many patients with CML as a distinct outcome other than overall survival (OS). This is driven by the absence of long-term safety data of TKIs beyond 10 years and the idea of reducing severe and mild TKIrelated adverse effects, which may result in improved quality of life (QoL). ${ }^{10,11}$ Enabling this approach are the long-term outcomes in the different TKI trials showing that a substantial proportion of patients may achieve a deep molecular response (DMR) ${ }^{6,12-15}$ and maintain it after discontinuation of the medication. ${ }^{16}$ This shift in therapy goals is still debated and has not yet been adopted in routine clinical care outside of clinical trials. This review discusses points for and against widely adopting TFR as a clinical outcome above OS in routine practice.

\section{TFR and Factors That Influence It}

\section{What Is TFR?}

TFR has been defined as the maintenance of stable low levels of minimal residual disease (MRD) or undetectable MRD without the need for ongoing treatment. ${ }^{17}$ Some investigators consider this an operational definition of cure, ${ }^{17}$ as opposed to a functional one for those remaining on therapy as coined by John Goldman. ${ }^{18} \mathrm{MRD}$ is measured with real-time PCR of the BCR-ABL transcript, with the resulting measurement defining degrees of molecular 
response. Major molecular response (MMR) is a BCR$\mathrm{ABL} \leq 0.1 \%$ (3-log reduction), and DMR is a BCR-ABL $\leq 0.01 \%$ (4-log reduction; MR4). As discussed, maintenance of prolonged responses correlates with favorable outcomes and near-normal OS. Patients now need to maintain an MMR or deeper response without restarting therapy to remain in TFR. This is not a novel idea, as it was observed in patients with CML previously treated with interferon who had to stop the drug but continued to experience cytogenetic remission despite detectable BCR-ABL transcripts. ${ }^{19,20}$ This was the initial proof of concept that TFR was possible in CML and that its principles could be extrapolated to TKI therapy.

\section{CML and Patient-Related Factors Influencing TFR}

Important questions to ask are in whom and when is it appropriate to attempt TFR? Discontinuation trials have used different inclusion criteria to consider stopping treatment. Apart from molecular responses determining disease control, several patient factors need to be considered before attempting discontinuation. Not all CML is the same, and not all patients have the same risks related to disease progression, response to TKIs, age, or comorbidities.

Disease risk in CML plays an important part in the decision to discontinue therapy. Patients at high risk of leukemia-related death (LRD), as assessed by a risk assessment score, should probably remain on TKI treatment to avoid this outcome. Risk assessment scores such as the Sokal score ${ }^{21}$ have been used since the pre-TKI era and continue to be valid in predicting response and survival. Most recently, other scores, such as the EUTOS long-term survival score (ELTS), try to more accurately predict the probability of LRD in patients treated with imatinib, ${ }^{22}$ because LRD is not a frequent outcome in patients with CML anymore. ELTS has better prediction capacity in LRD because the weight of age is lower in this score. ${ }^{23}$ Even though this score classifies patients more precisely, the Sokal score has historically been used in clinical trials and in some proposed optimal criteria for discontinuation..$^{3,17}$ Some guidelines ${ }^{3,17}$ recommend non-high Sokal scores to attempt TFR, but this is a flexible point, depending on other factors that are further discussed later.

Patients with CML may present with additional cytogenetic abnormalities to the standard translocation $(9 ; 22)(\mathrm{q} 34 ; \mathrm{q} 11)$. Additional cytogenetic abnormalities are considered to have worse prognosis and response to TKIs, ${ }^{24-26}$ which is why patients bearing these clonal abnormalities should not be considered for TFR. Special clinical trials for this group that comprises only approximately $5 \%$ to $7 \%$ of patients with $\mathrm{CML}^{24,25,27}$ should be considered if TFR is to be sought as an outcome for them in the future.

Age is another driver for patients and physicians to consider an attempt at TFR. Age is important in prognosis and outcomes, ${ }^{28}$ and is included and weighed into risk assessment scores. Different age groups have distinct behaviors and lifestyles, work and careers, financial situations, and goals. Patients and physicians may be more inclined to consider drug discontinuation among younger age groups who may not wish to be tied to a prescription medication throughout their lives. This especially applies to women who are considering pregnancy, as outlined later. Everyone has the right to attempt TFR in the proper medical context, with age itself not being an indication or contraindication for this. Decision-making is influenced by age but not dictated by it.

Comorbidities are an essential element of decisionmaking with regard to which TKI to prescribe as first-line therapy and, along with disease risk, age, and adverse effect profile, are considered when choosing a TKI upfront. Guidelines ${ }^{3,29,30}$ exist with recommendations for appropriate TKI prescription. Imatinib and bosutinib are fairly safe, and no strong contraindication exists to their use. Dasatinib might not be appropriate in the setting of previous lung disease, including pulmonary hypertension and fibrosis. Nilotinib should be avoided in patients with a history of cardiovascular disease and diabetes. The choice of TKI as a result of comorbidities might ultimately play a role in the possibility and chances for a patient to attempt TFR. As discussed later, second-generation TKIs (2g-TKIs) are more potent and can achieve deeper and faster molecular responses than imatinib, ${ }^{30}$ providing a better opportunity for TFR.

Feasibility and Previous Treatment-Related Factors Identifying a patient suitable for CML treatment discontinuation is a first step toward attempting TFR, with a second and equally important step being determining that CML has had an appropriate duration and depth of response to TKI treatment. These factors have been associated with better chances of achieving and maintaining TFR in discontinuation trials and are part of general recommendations. ${ }^{3,29-31}$ More than 50 TKI discontinuation trials have been published, ${ }^{32}$ all of them agreeing on certain depth and duration of response, but criteria vary across them. ${ }^{16}$

The depth of molecular response has shown some correlation with probability of TFR. As mentioned, different criteria have been used across studies, with some requiring $\geq \mathrm{MR} 4$ or $\geq \mathrm{MR} 4.5$ to be achieved before attempting TFR. However, some data show that MMR and not complete molecular response (5-log 
reduction) can have significant sustained TFR, ${ }^{33}$ with others reporting higher risk of molecular relapse. ${ }^{34}$ Overall, some degree of depth of response is required, but a specific cutoff is currently unknown. Therefore, to clarify this question, TFR should only be attempted in patients with a response less than MR4 (DMR) within a clinical trial setting.

Duration of DMR might be more important than overall duration of TKI treatment, as shown in prognostic modeling from the EURO-SKI trial, ${ }^{35}$ but specifically designed trials are needed to explore this aspect and allow recommendations. ${ }^{32}$ In addition, the velocity at which the BCR-ABL transcript decreases when starting treatment is prognostic of disease progression, ${ }^{36,37}$ possibly influencing future TFR attempts and opening the door to more widespread upfront use of potent $2 \mathrm{~g}$-TKIs. Halving time in the first 3 months was the strongest independent predictor of sustained TFR in a recent study. ${ }^{38}$ There is no clear evidence showing that changing therapy from imatinib to a $2 \mathrm{~g}$-TKI will achieve a deeper molecular response and allow an attempt at discontinuation, with this practice being controversial. ${ }^{30}$

After factoring in the previously discussed conditions, patients might be eligible to attempt TFR. Table 1 summarizes criteria for appropriately selecting patients for TFR. It is important to note that only approximately $40 \%$ to $50 \%$ of patients will attain a $\mathrm{DMR}^{6,13,14}$ with TKIs and will therefore be eligible to discontinue treatment. This number does not account for patients not eligible based on any of the other criteria. Once TFR is attempted, data from the imatinib discontinuation trials estimate a long-term average of sustained TFR of approximately $40 \%$ to $50 \%{ }^{39,40}$ Similarly, dasatinib discontinuation trials reported approximately $48 \%$ to $63 \%^{41-43}$ maintenance of TFR and nilotinib trials reported $48 \%$ to $68 \%{ }^{44-46}$ A small trend favors $2 \mathrm{~g}$-TKIs in the rates of achieving sustained TFR. Detailed results of the discontinuation trials and their inclusion characteristics are outside of the scope of this review and can be found elsewhere. ${ }^{16,47,48}$ No evidence is available regarding discontinuation of bosutinib or ponatinib.

\section{Table 1. Comparison of Proposed Optimal Criteria for Attempting Treatment-Free Remission}

\begin{tabular}{|c|c|c|c|c|}
\hline NCCN Guidelines $2019^{29}$ & ELN Guidelines $2020^{30}$ & ESMO Guidelines $2017^{3}$ & Hughes et al ${ }^{17}$ & $\begin{array}{l}\text { French CML Study Group } \\
\text { Recommendations }^{31}\end{array}$ \\
\hline Age $\geq 18$ y & - & - & - & Age $>18 y$ \\
\hline- & - & $\begin{array}{l}\text { Sokal score }{ }^{21} \text { non-high at } \\
\text { diagnosis }\end{array}$ & $\begin{array}{l}\text { Sokal score }{ }^{21} \text { non-high at } \\
\text { diagnosis }\end{array}$ & - \\
\hline $\begin{array}{l}\text { Chronic-phase CML (no prior } \\
\text { blast- or accelerated-phase } \\
\text { CML) }\end{array}$ & Chronic-phase disease & Chronic-phase disease & Chronic phase only & Chronic phase only \\
\hline TKI therapy for $\geq 3 y$ & $\begin{array}{l}\text { TKI therapy }>5 y^{a} \text { or } \\
>4 \text { y for } 2 g-T K I\end{array}$ & TKI therapy $>5 y$ & TKI therapy $>8 y$ & TKI therapy $>5 y$ \\
\hline $\begin{array}{l}\text { Prior evidence of quantifiable } \\
\text { BCR-ABL1 transcript }\end{array}$ & $\begin{array}{l}\text { Typical b2a2 or b3a2 } \\
\text { BCR-ABL1 transcript }\end{array}$ & $\begin{array}{l}\text { Typical b2a2 or b3a2 BCR- } \\
\text { ABL1 transcript or atypical } \\
\text { quantifiable transcript }\end{array}$ & $\begin{array}{l}\text { Typical b2a2 or b3a2 (e13a2 } \\
\text { or } \\
\text { e14a2) BCR-ABL1 transcript }\end{array}$ & $\begin{array}{l}\text { e13a2, e14a2, or e13a2 }+ \\
\text { e14a2 BCR-ABL1 transcript }\end{array}$ \\
\hline $\begin{array}{l}\text { Stable molecular response } \\
\text { (MR4; BCR-ABL1 } \leq 0.01 \% \text { ) } \\
\text { for } \geq 2 \text { y on } \geq 4 \text { tests } \geq 3 \\
\text { mo apart }\end{array}$ & $\begin{array}{l}\text { DMR }>3 \text { y if MR4 } \\
\text { DMR }>2 \text { y if MR4.5 } \\
\text { MR4 or greater }>2 y\end{array}$ & $\begin{array}{l}\text { MR4.5 reached } \\
\text { Duration of DMR (MR4 } \\
\text { or MR4.5) }>2 \mathrm{y}\end{array}$ & $\begin{array}{l}\text { MR4.5 depth of DMR } \\
\text { Duration of DMR }>2 y\end{array}$ & $\begin{array}{l}\text { MR4.5 in } \geq 4 \text { consecutive tests } \\
\text { Duration of DMR } \geq 2 y\end{array}$ \\
\hline $\begin{array}{l}\text { Access to reliable } \mathrm{qPCR} \text { with } \\
\text { sensitivity detection of at least } \\
\text { MR4.5 with results within } 2 \text { wk }\end{array}$ & $\begin{array}{l}\text { Access to high-quality qPCR } \\
\text { with rapid turnaround test } \\
\text { results }\end{array}$ & $\begin{array}{l}\text { Institutional criteria met: } \\
\text { 1. Availability of high-quality } \\
\text { qPCR } \\
\text { 2. Turnaround results within } \\
4 \mathrm{wk}\end{array}$ & $\begin{array}{l}\text { Institutional criteria } \\
\text { met: } \\
\text { 1. Availability of high-quality } \\
\text { qPCR } \\
\text { 2. Turnaround results } \\
\text { within } 4 \text { wk }\end{array}$ & - \\
\hline $\begin{array}{l}\text { Monthly molecular testing for } \\
1 \text { y, every } 6 \text { wk for second year, } \\
\text { and every } 12 \text { wk thereafter }\end{array}$ & $\begin{array}{l}\text { Monthly molecular testing for } \\
6 \text { mo, every } 2 \text { mo for months } \\
6-12 \text {, and every } 3 \text { mo } \\
\text { thereafter }\end{array}$ & 3. PCR capacity every $4-6$ wk & 3. PCR capacity every $4-6 \mathrm{wk}$ & - \\
\hline $\begin{array}{l}\text { Resumption of TKI within } 4 \text { wk } \\
\text { of loss of MMR }\end{array}$ & $\begin{array}{l}\text { Motivated patient with } \\
\text { structured communication }\end{array}$ & $\begin{array}{l}\text { 4. Structured follow-up to } \\
\text { enable rapid intervention } \\
\text { if BCR-ABL1 is increasing }\end{array}$ & $\begin{array}{l}\text { 4. Structured follow-up to } \\
\text { enable rapid intervention } \\
\text { if BCR-ABL1 is increasing }\end{array}$ & - \\
\hline $\begin{array}{l}\text { Consultation with CML } \\
\text { specialty center to review } \\
\text { appropriateness of TKI } \\
\text { discontinuation }\end{array}$ & $\begin{array}{l}\text { First-line therapy, or second- } \\
\text { line if intolerance was reason } \\
\text { for TKI change } \\
\text { No prior treatment failure }\end{array}$ & $\begin{array}{l}\text { Optimal response to first-line } \\
\text { therapy }\end{array}$ & $\begin{array}{l}\text { Optimal response to } \\
\text { first-line therapy }\end{array}$ & $\begin{array}{l}\text { No allo-SCT, suboptimal } \\
\text { response or warning, } \\
\text { progression, or resistance }\end{array}$ \\
\hline
\end{tabular}

Abbreviations: 2g-TKI, second-generation tyrosine kinase inhibitor; allo-SCT, allogeneic stem cell transplant; CML, chronic myeloid leukemia; DMR, deep molecular response; ELN, European LeukemiaNet; ESMO, European Society for Medical Oncology; MMR, major molecular response; MR4, molecular response of 4-log reduction; MR4.5, molecular response of 4.5-log reduction; QPCR, quantitative PCR; TKI, tyrosine kinase inhibitor.

aptimal. 


\section{QoL Aspects}

QoL has improved substantially since TKIs became standard therapy for CML. ${ }^{49}$ Even though huge strides have been made in this area, patients with CML receiving TKIs still do not have QoL equal that of the general population. This is especially significant in younger patients (age 18-39 y) and women, who have been shown to present with limitations in work and daily activities due to physical and emotional problems linked to treatment and disease. ${ }^{10}$ Common adverse effects vary among TKIs, but fatigue, muscle pains, nausea and vomiting, and edema are frequently encountered. ${ }^{50}$

Because QoL is not equal to that of the general population, some investigators proposed that TKI discontinuation would bring benefits to patients with CML and avoid major adverse effects, such as pleural effusion and cardiovascular events. A specific study examined QoL changes in patients who discontinued imatinib, showing improvement in TKI-related symptoms but, in contrast, the appearance of new musculoskeletal pain, fatigue, and pruritus. ${ }^{51}$ Overall, some benefit was noticed in patients, but no significant improvement in physical or mental health was reported with TKI discontinuation. Treatment discontinuation has prompted the identification of TKI withdrawal syndrome, ${ }^{52}$ characterized mainly by musculoskeletal pain, which can last for months. It is managed with acetaminophen, nonsteroidal anti-inflammatory drugs, or steroids and can occur in approximately $20 \%$ to $40 \%$ of patients. It seems that TKI withdrawal can occur regardless of the TKI agent used. ${ }^{53,54}$ The appearance of TKI withdrawal syndrome may abrogate some of the benefit of discontinuing therapy with the goal of relieving symptoms and improve QoL, although it is easily treated.

Another consideration for attempting TFR in women of childbearing age is that they may wish to become pregnant. TKIs are not known to severely affect fertility, but evidence suggests that they can have effects on fetal development and predispose patients to poor obstetric outcomes. ${ }^{55}$ Breastfeeding while receiving TKIs is not recommended, because imatinib, nilotinib, and dasatinib can be found in breast milk, with no data for bosutinib. Even though pregnancy can be carried out safely in patients with CML with appropriate planning, ${ }^{55}$ with some cases of uneventful pregnancies while receiving TKI therapy, ${ }^{56}$ most still advocate for TFR as a better goal for this patient population, or for a conversion of therapy to interferon. ${ }^{55}$

\section{Patient Preferences}

Just because patients are good candidates and meet criteria to attempt TFR does not mean that they are actually willing to discontinue their TKI. Factoring in psychologic aspects, motivations, and preferences is a key aspect of this approach. Although several studies have shown that patients are willing to stop treatment, there is a fraction who are reluctant to embrace the idea, mainly driven by the fear of consequences, including risk of recurrence. ${ }^{5-60}$ Interestingly, many of these patients are receiving long-term TKI therapy. In contrast, numerous patients are motivated to discontinue treatment due to TKI toxicity and convenience, ${ }^{58}$ not to mention economic factors. ${ }^{57}$

Physicians must take into account potential psychologic issues that can be associated with TFR. Anxiety generated by fluctuating BCR-ABL levels during followup needs to be considered. ${ }^{54}$ It has been proposed that screening for potential psychologic issues associated with TFR should be part of routine monitoring in followup $^{54}$ although no validated or standardized method exists. Physicians must also take into account a possible perception or idea of failure that could arise in patients who do not achieve TFR and require return to treatment. Even though patients regain control of CML molecular response by restarting TKI without progression or loss of response, ${ }^{35,39-41,45}$ and a second attempt at discontinuation can be tried safely, ${ }^{61,62}$ the psychological impact on the patient cannot be predicted.

\section{Economic Factors}

Even though economic considerations should be a secondary reason for attempting TFR, they still play a significant role from the point of view of both the patient and the healthcare system. TFR might reduce the overall cost of treating CML by discontinuing expensive drugs that carry high yearly prices. From a patient perspective of needing to cover these costs by buying medication, it is a straightforward decision. As mentioned, patients are willing to attempt TFR for economic reasons, ${ }^{57}$ even though this ideally should not be a driver of decisionmaking.

One consideration with the use of 2 g-TKIs as firstline treatments has been that even if upfront costs are higher than with imatinib, after discontinuation, costeffectiveness will balance out and be favorable toward $2 \mathrm{~g}$-TKIs. This was investigated in a 10 -year simulation concluding that imatinib was still the most cost-effective approach even after incorporating TFR. ${ }^{63}$ When only considering TFR as the goal, the cost saved with imatinib was less than that with $2 \mathrm{~g}$-TKIs, because fewer patients can attempt TFR with imatinib. We must remember that, on average, $75 \%$ of patients continue on TKI therapy in the long term because they are not candidates for attempting TFR or will not be able to maintain TFR. This analysis does not justify starting 2g-TKI upfront for the sole purpose of achieving rapid TFR and improving cost-effectiveness of treatment. This was confirmed in an analytic model that showed that $2 \mathrm{~g}$-TKI price has to decrease significantly to become cost-effective compared with imatinib. ${ }^{64}$ 
The approval of generic $2 \mathrm{~g}$-TKIs may alter this balance and turn out to be a feasible strategy. Overall, a randomized trial between a higher upfront cost $2 \mathrm{~g}$-TKI with TFR attempt versus lifelong therapy on a cheaper drug such as imatinib is needed to clarify this question.

Regardless of the TKIs chosen upfront, some studies have shown that discontinuing TKI therapy is eventually a cost-effective strategy. ${ }^{65}$ Unfortunately, the more frequent BCR-ABL monitoring required with TFR surveillance and frequent physician visits have not been factored into studies, and the overall cost-effectiveness of this strategy requires further research.

\section{Monitoring Capacity and Physician Aspects}

Monitoring capacity is a key element in attempting TFR. Guidelines have clear recommendations on how to monitor the BCR-ABL transcript once drug discontinuation has occurred ${ }^{3,29,30}$ (Table 1). Rapid test result turnaround within 2 to 4 weeks is suggested. ${ }^{3,17,29,30}$ These strict guidelines pose important problems for institutions and physicians that may not have the resources available to follow them. Attempting TFR with a lack of capacity to monitor is discouraged. Physicians caring for patients with CML require more education on guidelines and monitoring if they are to attempt TFR. ${ }^{66}$ When we extrapolate data from routine monitoring while on treatment, it has been shown that guidelines are not consistently translated into routine practice, with fewer than half of patients with CML followed appropriately. ${ }^{67,68}$ This is a dangerous situation when attempting TFR because patients require close follow-up, especially in the first 6 months when most relapses occur. ${ }^{69}$ Barriers identified for physicians adhering to guidelines include resource availability and lack of time to search guidelines. ${ }^{68}$ These need to be addressed if safe discontinuation is to be performed routinely in clinical practice and not only in specialized centers.

Patients need to be willing to commit to the monitoring schedules recommended by physicians. Only approximately $50 \%$ of patients adhere to their monitoring schedule while on treatment. ${ }^{70}$ To achieve a safe and successful TFR, compliant behavior requires reinforcement. Recently, a less frequent monitoring schedule model was proven safe. ${ }^{71}$ This might open the door to more physicians being able to offer TFR when they previously could not due to patients' financial constraints. A laxer approach might also be easier for patients and physicians to follow with better compliance results.

\section{Conclusions}

TFR is an attractive outcome that should be considered for appropriate patients for many different reasons, including QoL, long-term adverse effect avoidance, economic implications, and even as a possible operational cure. Regardless of these considerations, we must remember that TFR is not yet an outcome that applies to everyone. Roughly $75 \%$ of patients continue on treatment with currently available therapies. Only $50 \%$ are candidates to attempt TFR under ideal circumstances due to patient-related factors, CML response to treatment, and monitoring capacity. Of these, half maintain
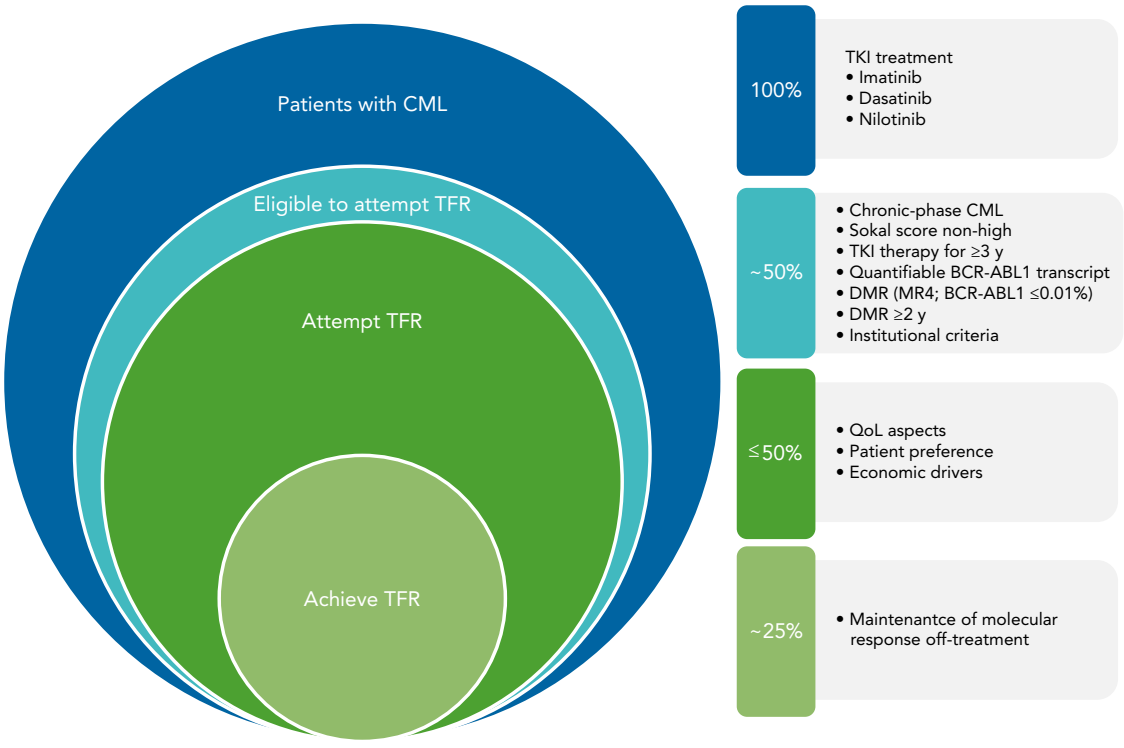

Figure 1. Representation of patients who attempt and achieve TFR. Bosutinib and ponatinib are not included because there is no evidence of TFR with these TKIs. QoL and economic drivers may play a positive role in attempting TFR, whereas patient preferences might be positive or negative drivers. Other clinical considerations must be taken into account when deciding to attempt TFR.

Abbreviations: DMR, deep molecular response; QoL, quality of life; TFR, treatment-free remission; TKI, tyrosine kinase inhibitor. 
stable BCR-ABL transcripts without treatment reinitiation (Figure 1). There is definitely room for improvement so that more patients can benefit from this approach. Our focus, though, should remain maintaining next-to-normal OS with the least harm possible through our interventions. This opens the door to focusing on alternative treatment approaches for those unable to stop TKIs altogether, such as reduced TKI dosing as maintenance. ${ }^{33,72}$ This might prove to be an effective therapy with many of the benefits that TFR offers, including fewer dose-related adverse effects and appropriate disease control. This approach may apply to a wider population, but further research is needed before we are able to extend it to routine clinical practice.

TFR research is currently focusing on different strategies to increase the number of patients who can achieve successful discontinuation. A consolidative approach using more potent TKIs such as ponatinib after achieving DMR to further deepen responses (ClinicalTrials.gov identifier: NCT04043676), or using interferon maintenance after discontinuation (NCT03117816). The combination of medications such as interferons, ruxolitinib, or asciminib with TKIs to optimize responses (NCT02001818,
NCT01657604, NCT01872442, NCT03831776, NCT03610971, and NCT04216563) is another strategy used in many trials, both as initial therapy or after TFR attempts have been made. Before applying these strategies in clinical practice, trials will need to show further benefits to our current approach and increase eligibility for TFR, achieve successful and durable TFR, and improve QoL while remaining economically feasible. TFR might remain a desirable outcome for the near future but is not one that fits all patients.

\section{Acknowledgments}

We wish to thank Yashoda Valliere for her valuable input on the figure design.

Submitted March 25, 2020; accepted for publication July 23, 2020

Disclosures: Dr. Garcia-Horton has disclosed that he has no financial interests, arrangements, affiliations, or commercial interests with the manufacturers of any products discussed in this article or their competitors. Dr. Lipton has disclosed that he receives grant/research support from Novartis, Bristol-Myers Squibb, Pfizer, and Takeda, and is a scientific adviser for Pfizer and Takeda.

Correspondence: Jeffrey H. Lipton, MD, PhD, Division of Medical Oncology and Hematology, Princess Margaret Cancer Centre, 610 University Avenue, Toronto, ON, M5G 2M9, Canada. Email: jeff.lipton@uhn.ca

\section{References}

1. O'Brien SG, Guilhot F, Larson RA, et al. Imatinib compared with interferon and low-dose cytarabine for newly diagnosed chronic-phase chronic myeloid leukemia. N Engl J Med 2003;348:994-1004. https://doi.org/ 10.1056/NEJMoa022457

2. National Cancer Institute Surveillance, Epidemiology, and End Results Program. Cancer Stat Facts: Leukemia - Chronic Myeloid Leukemia (CML). Accessed April 30, 2020. Available at: https://seer.cancer.gov/ statfacts/html/cmyl.html

3. Hochhaus A, Saussele S, Rosti G, et al. Chronic myeloid leukaemia: ESMO clinical practice guidelines for diagnosis, treatment and follow-up. Ann Oncol 2017;28(Suppl 4):iv41-51.

4. Sasaki K, Strom SS, O'Brien S, et al. Relative survival in patients with chronic-phase chronic myeloid leukaemia in the tyrosine-kinase inhibitor era: analysis of patient data from six prospective clinical trials. Lancet Haematol 2015;2:e186-193. https://doi.org/10.1016/S2352 3026(15)00048-4

5. Bower H, Björkholm M, Dickman PW, et al. Life expectancy of patients with chronic myeloid leukemia approaches the life expectancy of the general population. J Clin Oncol 2016;34:2851-2857. https://doi.org/10 1200/JCO.2015.66.2866

6. Hochhaus A, Larson RA, Guilhot F, et al. Long-term outcomes of imatinib treatment for chronic myeloid leukemia. N Engl J Med 2017;376: 917-927. https://doi.org/10.1056/NEJMoa1609324

7. Wang $Q$, Jiang $C$, Zhang $Y$, et al. Cardiovascular mortality among chronic myeloid leukemia patients in the pre-tyrosine kinase inhibitor (TKI) and TKI eras: a Surveillance, Epidemiology and End Results (SEER) analysis. Leuk Lymphoma 2020;61:1147-1157. https://doi.org/10.1080/10428194. 2019.1711074

8. Miranda MB, Lauseker M, Kraus MP, et al. Secondary malignancies in chronic myeloid leukemia patients after imatinib-based treatment: longterm observation in CML Study IV. Leukemia 2016;30:1255-1262. https:// doi.org/10.1038/leu.2016.20

9. Brunner AM, Campigotto F, Sadrzadeh H, et al. Trends in all-cause mortality among patients with chronic myeloid leukemia: a Surveillance, Epidemiology, and End Results database analysis. Cancer 2013;119: 2620-2629. https://doi.org/10.1002/cncr.28106

10. Efficace F, Baccarani M, Breccia M, et al. Health-related quality of life in chronic myeloid leukemia patients receiving long-term therapy with

imatinib compared with the general population. Blood 2011;118: 4554-4560. https://doi.org/10.1182/blood-2011-04-347575

11. Cortes JE, Jimenez CA, Mauro MJ, et al. Pleural effusion in dasatinib-treated patients with chronic myeloid leukemia in chronic phase: identification and management. Clin Lymphoma Myeloma Leuk 2017;17:78-82. https://doi.org/10.1016/ j.clml.2016.09.012

12. Hehlmann R, Müller MC, Lauseker M, et al. Deep molecular response is reached by the majority of patients treated with imatinib, predicts survival, and is achieved more quickly by optimized high-dose imatinib: results from the randomized CML-Study IV. J Clin Oncol 2014;32:415-423. https://doi.org/10.1200/JCO.2013.49.9020

13. Cortes JE, Saglio G, Kantarjian HM, et al. Final 5-year study results of DASISION: the Dasatinib Versus Imatinib Study in Treatment-Naïve Chronic Myeloid Leukemia Patients trial. J Clin Oncol 2016;34:2333-2340. https://doi.org/10.1200/JCO.2015. 64.8899

14. Hochhaus A, Saglio G, Hughes TP, et al. Long-term benefits and risks of frontline nilotinib vs imatinib for chronic myeloid leukemia in chronic phase: 5-year update of the randomized ENESTnd trial. Leukemia 2016, 30:1044-1054. https://doi.org/10.1038/leu.2016.5

15. Cortes JE, Gambacorti-Passerini C, Deininger MW, et al. Bosutinib versus imatinib for newly diagnosed chronic myeloid leukemia: results from the randomized BFORE trial. J Clin Oncol 2018;36:231-237. https://doi.org/ 10.1200/JCO.2017.74.7162

16. Cortes J, Rea D, Lipton JH. Treatment-free remission with first- and second-generation tyrosine kinase inhibitors. Am J Hematol 2019;94: 346-357.

17. Hughes TP, Ross DM. Moving treatment-free remission into mainstream clinical practice in CML. Blood 2016;128:17-23. https://doi.org/10.1182/ blood-2016-01-694265

18. Goldman J, Gordon M. Why do chronic myelogenous leukemia stem cells survive allogeneic stem cell transplantation or imatinib: does it really matter? Leuk Lymphoma 2006;47:1-7. https://doi.org/10.1080/ 10428190500407996

19. Lee MS, Kantarjian H, Talpaz M, et al. Detection of minimal residual disease by polymerase chain reaction in Philadelphia chromosomepositive chronic myelogenous leukemia following interferon 
therapy. Blood 1992;79:1920-1923. https://doi.org/10.1182/ blood.V79.8.1920.1920

20. Mahon FX, Delbrel X, Cony-Makhoul P, et al. Follow-up of complete cytogenetic remission in patients with chronic myeloid leukemia after cessation of interferon alfa. J Clin Oncol 2002;20:214-220. https:// doi.org/10.1200/JCO.2002.20.1.214

21. Sokal JE, Cox EB, Baccarani M, et al. Prognostic discrimination in "goodrisk" chronic granulocytic leukemia. Blood 1984;63:789-799. https:// doi.org/10.1182/blood.V63.4.789.789

22. Pfirrmann M, Baccarani M, Saussele $\mathrm{S}$, et al. Prognosis of long-term survival considering disease-specific death in patients with chronic myeloid leukemia. Leukemia 2016;30:48-56. https://doi.org/10.1038/ leu.2015.261

23. Baccarani M, Abruzzese E, Accurso V, et al. Managing chronic myeloid leukemia for treatment-free remission: a proposal from the GIMEMA CML WP. Blood Adv 2019;3:4280-4290. https://doi.org/10.1182/ bloodadvances. 2019000865

24. Fabarius A, Leitner A, Hochhaus A, et al. Impact of additional cytogenetic aberrations at diagnosis on prognosis of CML: long-term observation of 1151 patients from the randomized CML Study IV. Blood 2011;118: 6760-6768. https://doi.org/10.1182/blood-2011-08-373902

25. Luatti S, Castagnetti F, Marzocchi G, et al. Additional chromosomal abnormalities in Philadelphia-positive clone: adverse prognostic influence on frontline imatinib therapy: a GIMEMA working party on CML analysis. Blood 2012;120:761-767. https://doi.org/10.1182/blood2011-10-384651

26. Wang W, Cortes JE, Tang G, et al. Risk stratification of chromosomal abnormalities in chronic myelogenous leukemia in the era of tyrosine kinase inhibitor therapy. Blood 2016;127:2742-2750. https://doi.org/ 10.1182/blood-2016-01-690230

27. Alhuraiji A, Kantarjian $\mathrm{H}$, Boddu $\mathrm{P}$, et al. Prognostic significance of additional chromosomal abnormalities at the time of diagnosis in patients with chronic myeloid leukemia treated with frontline tyrosine kinase inhibitors. Am J Hematol 2018;93:84-90. https://doi.org/10.1002/ ajh.24943

28. Castagnetti F, Gugliotta G, Baccarani M, et al. Differences among young adults, adults and elderly chronic myeloid leukemia patients. Ann Oncol 2015;26:185-192. https://doi.org/10.1093/annonc/mdu490

29. Radich JP, Deininger M, Abboud CN, et al. NCCN Clinical Practice Guidelines in Oncology: Chronic Myeloid Leukemia, Version 1.2019. Accessed August 12, 2020. To view the most recent version, visit NCCN.org

30. Hochhaus A, Baccarani M, Silver RT, et al. European LeukemiaNet 2020 recommendations for treating chronic myeloid leukemia. Leukemia 2020; 34:966-984. https://doi.org/10.1038/s41375-020-0776-2

31. Rea $D, A m e S$, Berger $M$, et al. Discontinuation of tyrosine kinase inhibitors in chronic myeloid leukemia: recommendations for clinical practice from the French Chronic Myeloid Leukemia Study Group. Cancer 2018;124: 2956-2963. https://doi.org/10.1002/cncr.31411

32. Saglio G, Gale RP. Prospects for achieving treatment-free remission in chronic myeloid leukaemia. Br J Haematol 2020;190:318-327. https:// doi.org/10.1111/bjh.16506

33. Clark RE, Polydoros F, Apperley JF, et al. De-escalation of tyrosine kinase inhibitor therapy before complete treatment discontinuation in patients with chronic myeloid leukaemia (DESTINY): a non-randomised, phase 2 trial. Lancet Haematol 2019;6:e375-383. https://doi.org/10.1016/S23523026(19)30094-8

34. Benjamini $\mathrm{O}$, Kantarjian $\mathrm{H}$, Rios $\mathrm{MB}$, et al. Patient-driven discontinuation of tyrosine kinase inhibitors: single institution experience. Leuk Lymphoma 2014;55:2879-2886. https://doi.org/10.3109/10428194.2013. 831092

35. Saussele S, Richter J, Guilhot J, et al. Discontinuation of tyrosine kinase inhibitor therapy in chronic myeloid leukaemia (EURO-SKI): a prespecified interim analysis of a prospective, multicentre, non-randomised, trial. Lancet Oncol 2018;19:747-757. https://doi.org/10.1016/S1470-2045(18) 30192-X

36. Hanfstein B, Shlyakhto V, Lauseker M, et al. Velocity of early BCR-ABL transcript elimination as an optimized predictor of outcome in chronic myeloid leukemia (CML) patients in chronic phase on treatment with imatinib. Leukemia 2014;28:1988-1992. https://doi.org/10.1038/ leu.2014.153

37. Marin D, Ibrahim AR, Lucas $C$, et al. Assessment of BCR-ABL1 transcript levels at 3 months is the only requirement for predicting outcome for patients with chronic myeloid leukemia treated with tyrosine kinase inhibitors. J Clin Oncol 2012;30:232-238. https://doi.org/10.1200/ JCO.2011.38.6565
38. Shanmuganathan N, Branford S, Pagani I, et al. Early BCR-ABL1 kinetics are predictive of subsequent achievement of treatment-free remission [published online September 1, 2020]. Blood. doi.org/10.1182/ blood.2020005514

39. Etienne G, Guilhot J, Rea D, et al. Long-term follow-up of the French Stop Imatinib (STIM1) study in patients with chronic myeloid leukemia. J Clin Oncol 2017;35:298-305. https://doi.org/10.1200/ JCO.2016.68.2914

40. Ross DM, Branford S, Seymour JF, et al. Safety and efficacy of imatinib cessation for CML patients with stable undetectable minimal residual disease: results from the TWISTER study. Blood 2013;122:515-522. https://doi.org/10.1182/blood-2013-02-483750

41. Shah NP, García-Gutiérrez V, Jiménez-Velasco A, et al. Dasatinib discontinuation in patients with chronic-phase chronic myeloid leukemia and stable deep molecular response: the DASFREE study. Leuk Lymphoma 2020;61:650-659.

42. Kumagai T, Nakaseko C, Nishiwaki K, et al. Dasatinib cessation after deep molecular response exceeding 2 years and natural killer cell transition during dasatinib consolidation. Cancer Sci 2018;109:182-192. https:// doi.org/10.1111/cas.13430

43. Okada M, Imagawa J, Tanaka $\mathrm{H}$, et al. Final 3-year results of the dasatinib discontinuation trial in patients with chronic myeloid leukemia who received dasatinib as a second-line treatment. Clin Lymphoma Myeloma Leuk 2018;18:353-360.e1. https://doi.org/10.1016/ j.clml.2018.03.004

44. Nagafuji K, Matsumura I, Shimose T, et al. Cessation of nilotinib in patients with chronic myelogenous leukemia who have maintained deep molecular responses for 2 years: a multicenter phase 2 trial, Stop Nilotinib (NILSt). Int J Hematol 2019;110:675-682. https://doi.org/10.1007/ s12185-019-02736-5

45. Hochhaus A, Masszi T, Giles FJ, et al. Treatment-free remission following frontline nilotinib in patients with chronic myeloid leukemia in chronic phase: results from the ENESTfreedom study. Leukemia 2017;31: 1525-1531. https://doi.org/10.1038/leu.2017.63

46. Hughes TP, Boquimpani C, Takahashi N, et al. ENESTop 192-week results: treatment-free remission (TFR) in patients (pts) with chronic myeloid leukemia in chronic phase (CML-CP) after stopping second-line (2L) nilotinib (NIL) [abstract]. J Clin Oncol 2019;37(Suppl):Abstract 7005

47. Harrington $\mathrm{P}$, Radia $\mathrm{D}$, de Lavallade $\mathrm{H}$. What are the considerations for tyrosine kinase inhibitor discontinuation in chronic-phase chronic myeloid leukemia? Expert Rev Hematol 2020;13:213-222. https://doi.org/ 10.1080/17474086.2020.1717944

48. Mahon FX. Treatment-free remission in CML: who, how, and why? Hematology Am Soc Hematol Educ Program 2017;2017:102-109. https://doi.org/10.1182/asheducation-2017.1.102

49. Hahn EA, Glendenning GA, Sorensen MV, et al. Quality of life in patients with newly diagnosed chronic phase chronic myeloid leukemia on imatinib versus interferon alfa plus low-dose cytarabine: results from the IRIS study. J Clin Oncol 2003;21:2138-2146. https://doi.org/10.1200/ JCO.2003.12.154

50. Efficace F, Cannella L. The value of quality of life assessment in chronic myeloid leukemia patients receiving tyrosine kinase inhibitors. Hematology Am Soc Hematol Educ Program 2016;2016:170-179. https://doi.org/10.1182/asheducation-2016.1.170

51. Park JS, Lee SE, Jeong SH, et al. Change of health-related profiles after imatinib cessation in chronic phase chronic myeloid leukemia patients. Leuk Lymphoma 2016;57:341-347. https://doi.org/10.3109/ 10428194.2015.1049166

52. Richter J, Söderlund S, Lübking $A$, et al. Musculoskeletal pain in patients with chronic myeloid leukemia after discontinuation of imatinib: a tyrosine kinase inhibitor withdrawal syndrome? J Clin Oncol 2014;32:2821-2823. https://doi.org/10.1200/JCO.2014.55.6910

53. Berger MG, Pereira $B$, Rousselot $P$, et al. Longer treatment duration and history of osteoarticular symptoms predispose to tyrosine kinase inhibitor withdrawal syndrome. Br J Haematol 2019;187:337-346. https://doi.org/ 10.1111/bjh.16083

54. Saglio G, Sharf G, Almeida A, et al. Considerations for treatment-free remission in patients with chronic myeloid leukemia: a joint patientphysician perspective. Clin Lymphoma Myeloma Leuk 2018:18:375-379. https://doi.org/10.1016/j.clml.2018.04.005

55. Law AD, Dong Hwan Kim D, Lipton JH. Pregnancy: part of life in chronic myelogenous leukemia. Leuk Lymphoma 2017;58:280-287. https:// doi.org/10.1080/10428194.2016.1201571

56. Abruzzese E, Trawinska MM, Perrotti AP, et al. Tyrosine kinase inhibitors and pregnancy. Mediterr J Hematol Infect Dis 2014;6:e2014028. https:// doi.org/10.4084/mjhid.2014.028 
57. Goldberg S, Hamarman S. Patients with chronic myelogenous leukemia may not want to discontinue tyrosine kinase inhibitor therapy [abstract]. Blood 2015;126:Abstract 1584. https://doi.org/10.1182/blood.V126.23. 1584. 1584

58. Villemagne Sanchez LA, O'Callaghan C, Gough K, et al. Patient perceptions of treatment-free remission in chronic myeloid leukemia. Leuk Lymphoma 2018;59:406-415. https://doi.org/10.1080/10428194.2017. 1337114

59. Sanford D, Kyle R, Lazo-Langner A, et al. Patient preferences for stopping tyrosine kinase inhibitors in chronic myeloid leukemia. Curr Oncol 2014; 21:e241-249.

60. Breccia M, Efficace F, Sica S, et al. Adherence and future discontinuation of tyrosine kinase inhibitors in chronic phase chronic myeloid leukemia: a patient-based survey on 1133 patients. Leuk Res 2015;39:1055-1059. https://doi.org/10.1016/j.leukres.2015.07.004

61. Legros L, Nicolini FE, Etienne G, et al. Second tyrosine kinase inhibitor discontinuation attempt in patients with chronic myeloid leukemia. Cancer 2017;123:4403-4410. https://doi.org/10.1002/cncr.30885

62. Kim DDH BL, Forrest DL, et al. Second attempt of TKI discontinuation with dasatinib for treatment-free remission after failing first attempt with imatinib: Treatment-Free Remission Accomplished By Dasatinib (TRAD) trial [abstract]. Blood 2018;132(Suppl 1):Abstract 787

63. Yamamoto $\mathrm{C}$, Nakashima H, lkeda $\mathrm{T}$, et al. Analysis of the costeffectiveness of treatment strategies for CML with incorporation of treatment discontinuation. Blood Adv 2019;3:3266-3277. https:// doi.org/10.1182/bloodadvances.2019000745

64. Shih YT, Cortes JE, Kantarjian HM. Treatment value of second-generation BCR-ABL1 tyrosine kinase inhibitors compared with imatinib to achieve treatment-free remission in patients with chronic myeloid leukaemia: a modelling study. Lancet Haematol 2019;6:e398-408. https://doi.org/ 10.1016/S2352-3026(19)30087-0
65. Elias F, Gebran A, Said C, et al. Budget impact of treatment-free remission in treating chronic-phase Philadelphia-positive chronic myeloid leukemia in Lebanon. J Glob Oncol 2019;5:1-7.

66. Ritchie EK, Latremouille-Viau D, Guerin A, et al. Tyrosine kinase inhibitor therapy treatment and discontinuation in patients with chronic myeloid leukemia in chronic phase in the United States: a clinical practice perspective. Leuk Lymphoma 2019;60:1476-1484. https://doi.org/10.1080/ 10428194.2018.1538510

67. Goldberg SL, Cortes JE, Gambacorti-Passerini C, et al. First-line treatment selection and early monitoring patterns in chronic phase-chronic myeloid leukemia in routine clinical practice: SIMPLICITY. Am J Hematol 2017;92 1214-1223. https://doi.org/10.1002/ajh.24887

68. Goldberg SL, Akard LP, Dugan MJ, et al. Barriers to physician adherence to evidence-based monitoring guidelines in chronic myelogenous leukemia. J Oncol Pract 2015;11:e398-404. https://doi.org/10.1200/ JOP.2014.001099

69. Saußele S, Richter J, Hochhaus A, et al. The concept of treatment-free remission in chronic myeloid leukemia. Leukemia 2016;30:1638-1647. https://doi.org/10.1038/leu.2016.115

70. Dela Cruz JP, Staszewski H. A single center retrospective analysis of adherence to molecular monitoring guidelines in patients with chronic myeloid leukemia [abstract]. Blood 2016;128:Abstract 2365. https:// doi.org/10.1182/blood.V128.22.2365.2365

71. Shanmuganathan N, Braley JA, Yong ASM, et al. Modeling the safe minimum frequency of molecular monitoring for $\mathrm{CML}$ patients attempting treatment-free remission. Blood 2019;134:85-89. https://doi.org/ 10.1182/blood.2019000120

72. Fassoni AC, Baldow C, Roeder I, et al. Reduced tyrosine kinase inhibitor dose is predicted to be as effective as standard dose in chronic myeloid leukemia: a simulation study based on phase III trial data. Haematologica 2018;103:1825-1834. https://doi.org/10.3324/haematol.2018.194522 